\title{
Thermal methods for therapy of nonvariceal bleeding
}

\author{
DAVID FLEISCHER, MD
}

D FLEISCHER. Thermal methods for therapy of nonvariceal bleeding. Can J Gastroenterol1992;6(3):176-178. This presentation addresses the thermal methods for therapy of nonvariceal bleeding. The following subtopics will be considered: overview of thermal options, combination therapy, data, technique, conclusions regarding peptic ulcer therapy and unique situations.

Key Words: Endoscopic therapy, Gastrointestinal bleeding

\section{Méthodes thérapeutiques thermiques utilisées dans les cas d'hémorragies non variqueuses}

RÉSUMÉ: Ce texte passe en revue les méthodes thérapeutiques thermiques utilisées dans les cas d'hémorragies non variqueuses. Les thèmes suivants sont abordés: survol des options thermiques, traitements d'association, données, techniques, conclusions relatives au traitement de l'ulcère gastro-duodénal et cas particuliers.
$\mathrm{I}^{\mathrm{N}}$ N 1989, THE NATIONAL INSTITUTES of Health (NIH) Consensus Conference on Endoscopic Therapy of Peptic Ulcer Disease concluded that four endoscopic therapies of bleeding peptic ulcer should be considered: multipolar electrocoagulation (MPEC), heater probe, Nd:YAG laser and injection therapy (1). The MPEC and heat probe were rated most preferable because of their safety, efficacy, low cost and portability. The Nd:YAG laser was deemed effective but less desirable because it was less portable and more skill was required to use it. Monopolar electro- coagulation, electrohydrothermal therapy and microwave therapy are the thermal technologies which currently have little role.

\section{COMBINATION THERAPY}

Rutgeerts et al (2) has studied and popularized the method using combination therapy for peptic ulcer bleeding. By injecting the bleeding site with 1:10,000 adrenaline prior to the institution of thermal therapy, Rutgeerts' group believes that the efficacy of treatment can be increased. The logic is that the adrenaline will cause vasocon-
Georgetoun University Hospital, Washington, DC, USA

Correspondence and reprints: Dr David Fleischer, Chief, Endoscopy, Professor of Medicine, Georgetown University Hospital, 3800 Reservoir Road NW, Washington, DC 20007, USA striction which constricts the artery, making it less apt to bleed, and facilitates the heat sink effect (if there is less moving blood flowing through the artery, less heat will be carried away, making the thermal treatment more efficient). In addition, the edema which is caused from the injection will also cause some compression on the vessel making it less likely to bleed.

Some experimental work by Lam and colleagues (3) evaluated mural weakness and tissue effects induced by thermal and injection therapy in a porcine small bowel model. They wished to determine what thermal and injection therapies, both alone and in combination, are due to wall strength to provide information about the risk of perforation when combined therapies are employed. They determined the mural weakness was most marked two days after thermal injury wall strength returned to normal after four days. Alcohol injection alone and alcohol followed by BICAP or heater probe does not reduce wall strength. Adrenaline alone also does not reduce wall strength, but adrenaline followed by either BICAP or heater probe treatment decreases wall strength. In a clinical study by Rutgeerts and colleagues (2), adrenaline plus polidocanol was found to be more effective than adrenaline plus YAG laser therapy, which is more effective than adrenaline alone for bleeding peptic ulcers. 


\section{COMPARATIVE DATA}

In an attempt to understand better which of the thermal methods is most desirable, it is useful to review several studies comparing different endoscopic therapies. In a multicentre endoscopic trial, Jensen et al $(4,5)$ found that both the BICAP and heater probe were superior to no endoscopic therapy for patients with actively bleeding ulcers compared with nonbleeding ulcers with visible vessels. The BICAP and heater probe were similar when compared for number of days in the intensive care unit, number of blood transfusions, need for ulcer surgery, ulcer healing rates and mortality during hospitalization.

Matthewson et al (6) compared the $\mathrm{Nd}$ :YAG laser with heater probe for control of actively bleeding ulcers and nonbleeding visible vessels. There was no statistically significant difference in mortality between the groups, but rebleeding in laser-treated patients was less than in the control group and heater probe-treated patients. The authors (6) found the YAG laser superior to the heater probe.

Lin et al (7) randomized 61 patients with nonbleeding visible vessels to either heater probe treatment or conservative management without endoscopic therapy. There was no statistically significant difference between the two groups in rate of rebleeding; additionally, the assurance of ultimate hemostasis, number of blood transfusions required, duration of hospitalization and eventual mortality were similar. However, the need for emergency surgical intervention was less frequent in the heater probe group.

Hui and co-workers (8) did a randomized comparative study of laser photocoagulation, heater probe and bipolar electrocoagulation in treatment of actively bleeding ulcers. There was no control group in this study and the authors found the three treatment groups similar with regard to rate of rebleeding, duration of hospital stay and proportion of emergency surgery required. They stated that they preferred the bipolar electrocoagulation and heater probe over the YAG laser because the former two are less expen- sive (although the difference was not significant) and rebleeding in the heater probe group was twice that of the laser and electrocoagulation group.

Rutgeerts et al (2) compared the BICAP and YAG laser in patients with active bleeding ulcers and nonbleeding visible vessels, pretreating all lesions with 1:10,000 adrenaline. Hemostasis was similar in both groups and there was no difference in mortality.

\section{TECHNIQUE}

Treatment parameters: There has been renewed focus regarding the amount of power and pulse duration for the different thermal devices. Initially MPEC power was in the range of $50 \mathrm{~W}$ with 1 to $2 \mathrm{~s}$ pulses. Work by Jensen and Laine $(3,4,9)$ suggests that the depth of tissue effect (and possibly successful therapy) can be affected by power and pulse duration settings. They recommend $25 \mathrm{~W}$ and contact times of 10 to $14 \mathrm{~s}$. With the heater probe, $30 \mathrm{~J}$ is advised and contact times of 8 to 10 s required. The depth of injury can be increased by keeping the probe proximate to the treated area. With a YAG laser, the standard setting would be 70 to $80 \mathrm{~W}$ for 0.3 to $0.5 \mathrm{~s}$. Tissue effects will also vary with distance from the laser fibre to tissue because energy density will vary with distance (because the beam is divergent) in this noncontact method.

If a spurting artery is treated with a contact device (MPEC or heater probe), the device should be applied directly to the spurt of blood for a direct coaptive effect. The YAG laser's beam is aimed at and around the spurting artery to create some edema from the thermal injury.

There is no consensus on the best method for treating a visible vessel. The majority of experts believe that treating circumferentially around the vessel before treating its centre adds a safety margin of increased edema and vasoconstriction of the bleeding vessel. A minority opinion believes that direct pressure to the vessel is effective and minimizes injury to surrounding tissue. If a clot is encountered, the NIH Consensus Conference recommends that gentle washing be applied and if the clot does not come off, treatment is not indicated. However, if treatment is to be carried out, there are two approaches. Preinjection around the clot with adrenaline will cause vasoconstriction of the underlying vessel and the edema, and both constrict the vessel and form a mound which will evict the clot. Alternatively, a two-channel scope could be used with a grasping forceps placed through one of the channels to grab the clot. If bleeding ensues, a therapeutic device placed through the second channel could be poised for therapy.

\section{CONCLUSIONS REGARDING PEPTIC ULCERS}

MPEC, heater probe, and YAG laser therapy are all effective and safe for treating bleeding peptic ulcers. MPEC and heater probe appear to be preferable because captive coagulation can be used, a wash system is available and they are portable. A spurting artery should be treated in all incidences. Consideration for treating a visible vessel should be given because the frequency of rebleeding is approximately $50 \%$. If a clot is encountered over an ulcer and recent bleeding has occurred, one may begin with gentle washing. A decision as to whether an attempt should be made to provide further endoscopic treatment depends on the clinical setting.

\section{UNIQUE SITUATIONS}

Although the portability of the MPEC and heater probe make them desirable for treating peptic ulcers and should be considered as the first line of thermal therapy, because the laser can be used in a noncontact fashion, penetrate more deeply, treat a broader area and more rapidly treat multiple lesions, there are unique situations in which laser therapy is preferable to MPEC and heater probe. These conditions include watermelon stomach, multiple angiodysplasia and radiation proctitis. In addition, because penetration with the YAG laser is deeper, it is more effective than the contact devices for treating tumours of the gastrointestinal tract which bleed and for which endoscopic therapy is deemed appropriate. 


\section{REFERENCES}

1. Proceedings of the Consensus Conference on Therapeutic Endoscopy and Bleeding Ulcers. Gastrointest Endose 1990;36(Suppl): 1-64.

2. Rutgeerts P, Vantrappen C, Van Hootgem P, et al. Nd:YAG laser versus MPEC for treatment of severely bleeding ulcers. Gastrointest Endosc 1987;33:199-202.

3. Lam T, Newsome J, Rosen A, et al. Mural weakness and tissue effects induced by thermal and injection therapies in a porcine small bowel model. Gastrointest Endosc. (In press)

4. Jensen DM, Hirabayashi K, CURE Hemostasis Research Group. A study of coagulation depths with BICAP and heater probe to improve endoscopic hemostasis of bleeding peptic ulcers Gastrointest Endosc 1989;35:181. (Abst)

5. Jensen DM, Machicado GA, Kovacs TOG, et al. Controlled randomized study of heater probe and BICAP for hemostasis of severe ulcer bleeding. Gastroenterology 1988;94:A208. (Abst)

6. Matthewson K, Swain C, Bland M, Kirkham JS, Bown SG, Northfield TC. Randomized comparison of Nd:YAG laser, heater probe and no endoscopic therapy for bleeding peptic ulcers. Gastroenterology 1990;98:1239-44.
7. Lin MJ, Lee FY, Kang WM, et al. A controlled study of therapeutic endoscopy for peptic ulcers with non-bleeding visible vessel. Gastrointest Endosc 1990;36:241-6.

8. Hui WM, Ng N, Lok A, Lai C, Lan Y, Lam SV. A randomized comparison of laser photocoagulation, heater probe, and bipolar coagulation in the treatment of bleeding ulcers. Gastrointest Endosc 1991;37:299-304.

9. Laine L. Multipolar electrocoagulation in the treatment of active upper gastrointestinal hemmorhage: A prospective controlled trial. N Engl J Med 1987;316:1613-7. 


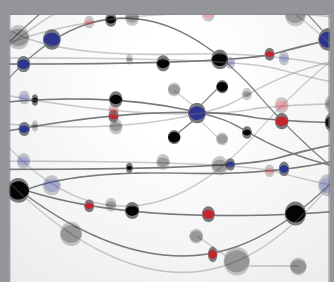

The Scientific World Journal
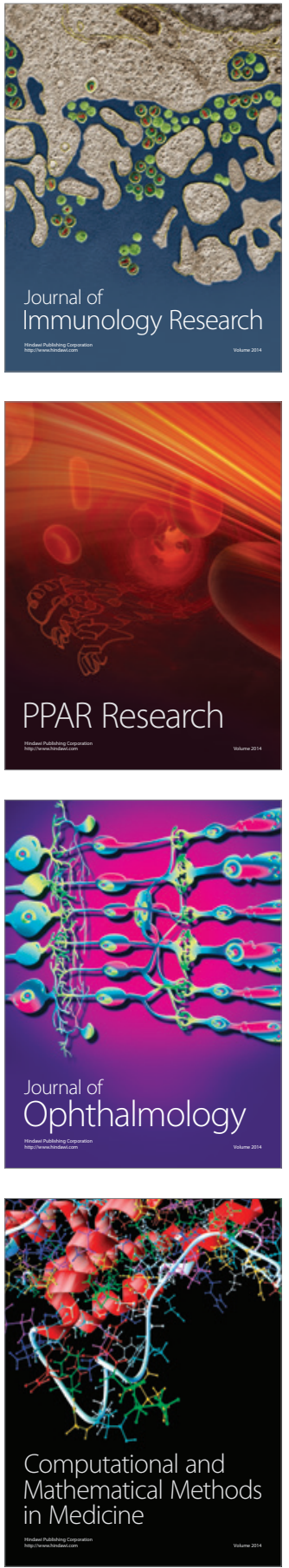

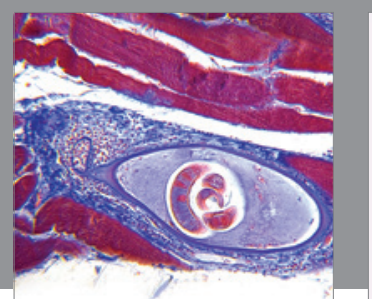

Gastroenterology Research and Practice

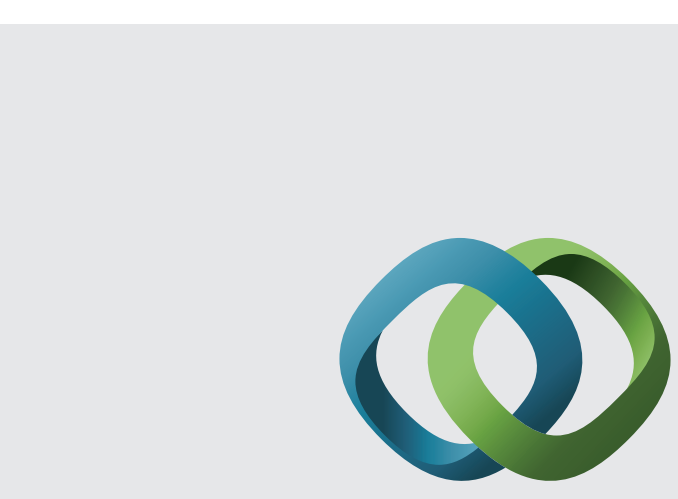

\section{Hindawi}

Submit your manuscripts at

http://www.hindawi.com
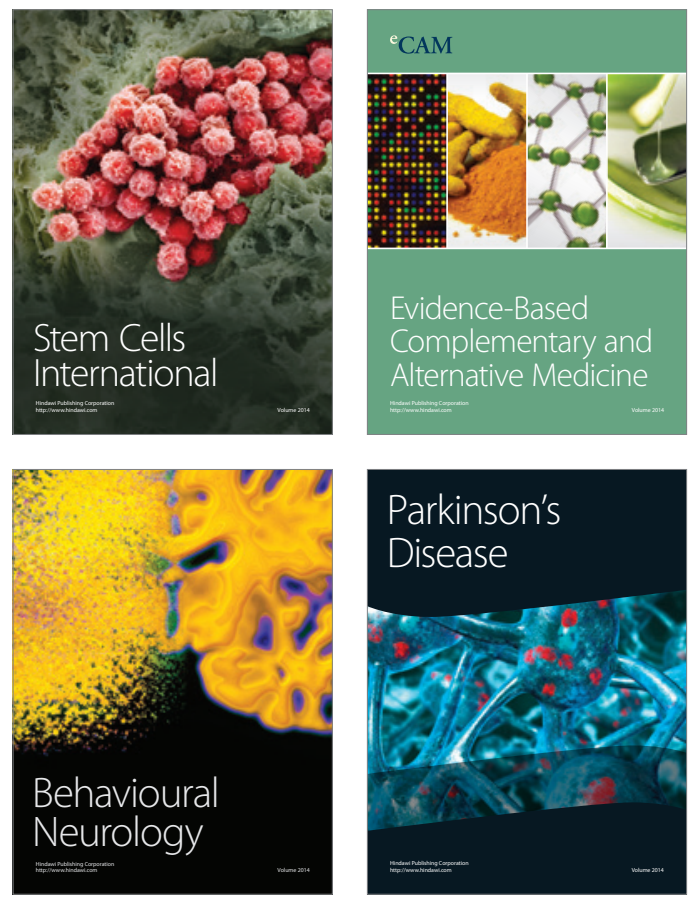
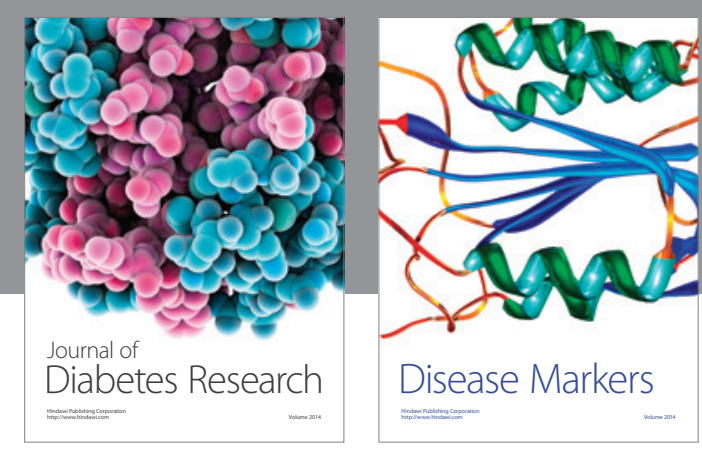

Disease Markers
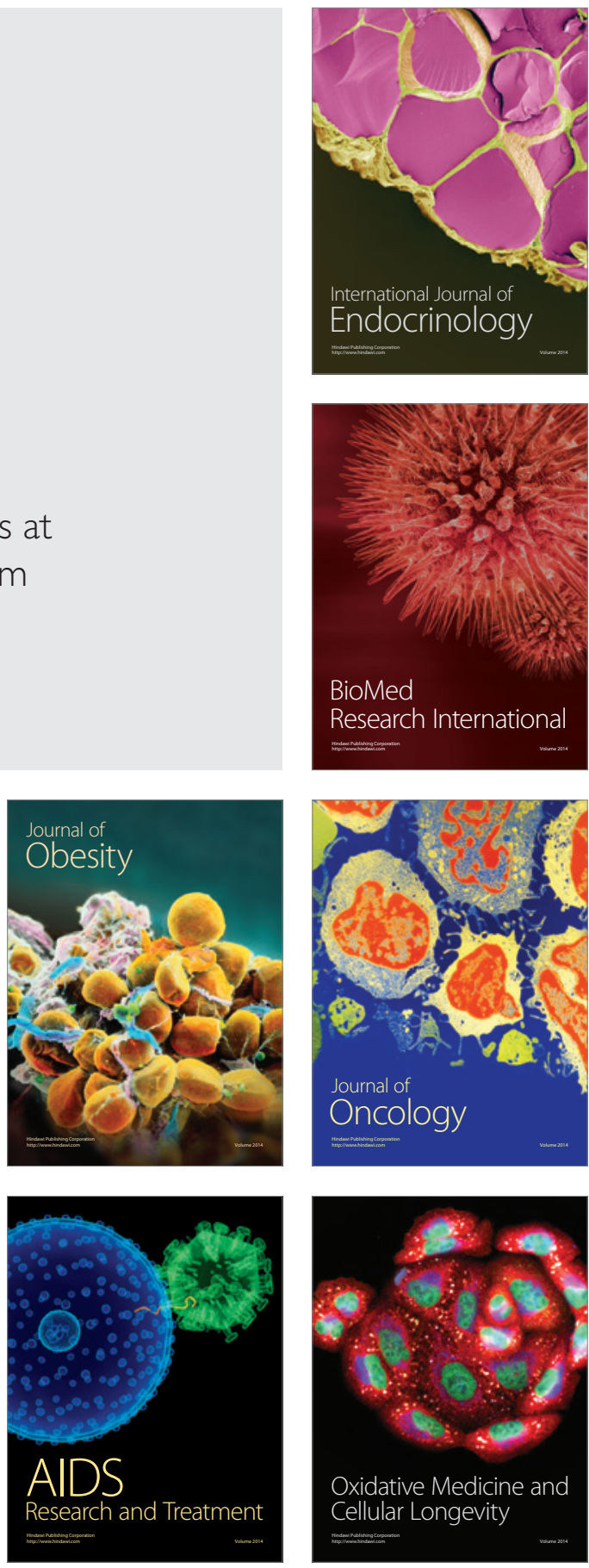